ANO 10 • NÚMERO $19 \cdot 2$ 2os 2013 • ORGANICOM

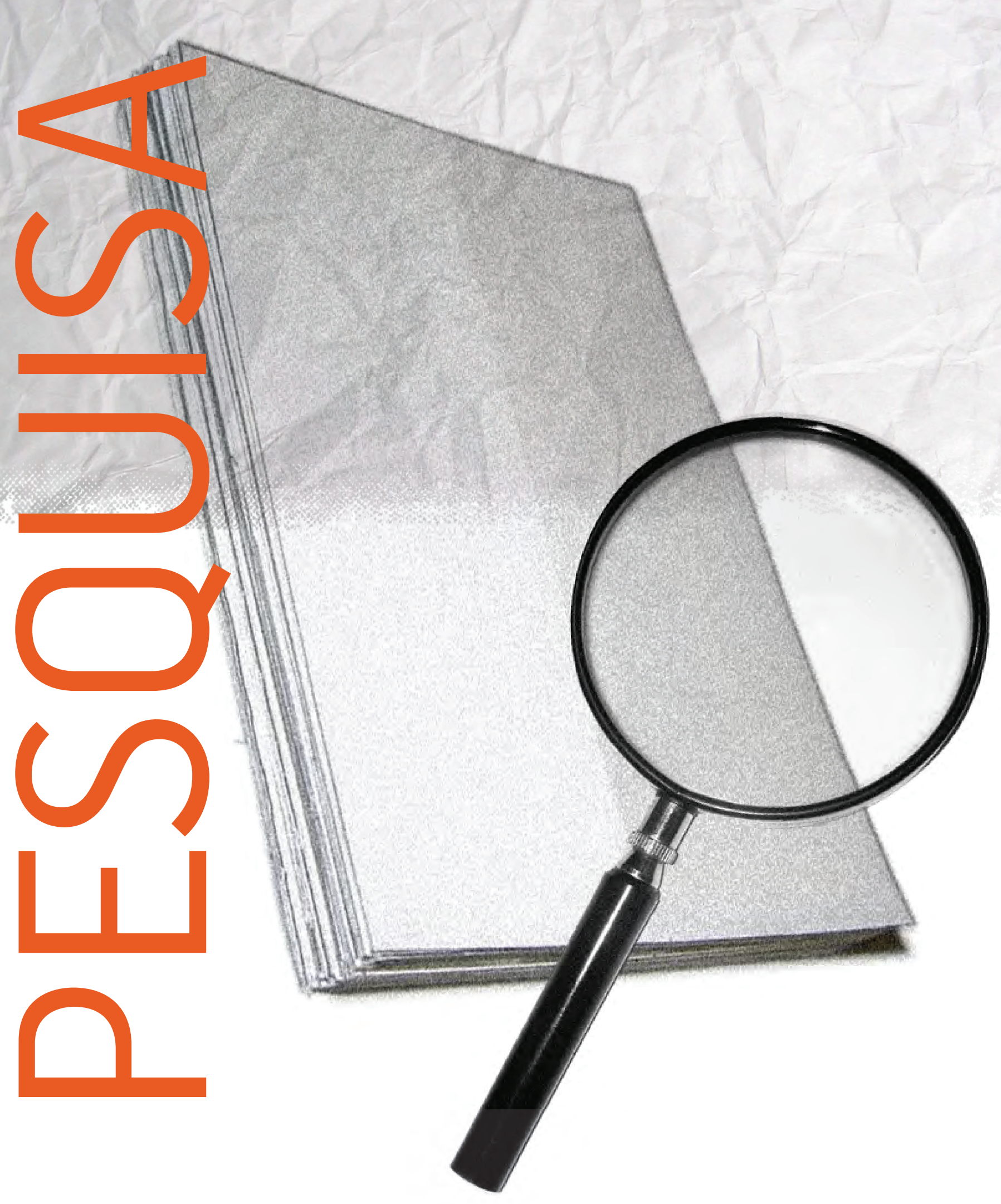




\title{
Informação, comunicação e comprometimento: um desafio para o engajamento do público interno
}

\author{
Information, communication and commitment: \\ a challenge for internal audience engagement
}

Información, comunicación y comprometimiento:

un desafío para el envolvimiento del público interno

\section{Ana Cristina Fachinelli}

- Doutora em Ciências da Informação e da Comunicação pela Université de Poitiers, França

- $\quad$ Pós-doutora em Inteligência Estratégica pela Universidad de Deusto, Espanha

- Professora do Centro de Ciências da Comunicação e do Programa de Pós-Graduação em Administração da Universidade de Caxias do Sul (UCS)

E-mail: afachinelli@gmail.com

\section{Jane Rech}

- Doutora em Comunicação Social pela Pontifícia Universidade Católica do Rio Grande do Sul (PUC-RS)

- Coordenadora do Curso de Relações Públicas no Centro de Ciências da Comunicação na Universidade de Caxias do Sul (UCS)

E-mail: janerech@terra.com.br

\section{Cintia Paese Giacomelo}

- $\quad$ Doutora em Administração pela Universidade Federal do Rio Grande do Sul (UFRGS)

- $\quad$ Professora da Universidade de Caxias do Sul (UCS)

- E-mail:cpaese1@ucs.br

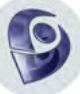

\section{Grazielle Betina Brandt}

- Doutora em Desenvolvimento Regional pela Université du Québec, Canadá

- Professora do curso de Comunicação Social e docente colaboradora do programa de Pós-Graduação em Desenvolvimento Regional na Universidade de Santa Cruz do Sul (Unisc)

- E-mail: grazibrandt@hotmail.com

\section{Mariana Tiburi Manozzo}

- $\quad$ Bacharel em Comunicação Social - Relações Públicas, pela Universidade de Caxias do Sul (UCS)

- E-mail:mtmanozzo@gmail.com 


\section{Resumo}

Ao considerar as implicações sociais das suas atividades, as organizações encontram desafios como 0 engajamento dos stakeholders. 0 artigo situa tal reflexão no âmbito do público interno das organizações, uma vez que o engajamento em projetos corporativos pode estar condicionado ao seu comprometimento com a organização. 0 objetivo da pesquisa foi estudar a informação e a comunicação e sua relação com o comprometimento. Os dados foram coletados utilizando-se escalas de medidas e analisados por meio de técnicas estatísticas multivariadas. Verificou-se que funcionários satisfeitos com as informações dos gestores, com maior acesso à comunicação vertical e a informações estratégicas, tendem a ser mais comprometidos.

\section{PALVRAS-CHAVE: INFORMAÇÃO•COMUNICAÇÃO•COMPROMETIMENTO• RESPONSABILIDADE SOCIAL EMPRESARIAL.}

\section{Abstract}

When considering social implications of their activities, organizations find it challenging to engage stakeholders. This article discusses this topic from the organization internal audience perspective, since their engagement level in corporate projects may vary according to their commitment to the organization. The purpose of this research was to study information and communication and how they are related to commitment. Data were collected using measurement scales, and analyzed with multivariate statistical techniques. The results indicated that employees who are pleased with the information they receive from their managers, and who have greater access to strategic information and vertical communication, tend to show higher commitment levels.

\section{KEYWORDS: INFORMATION • COMMUNICATION • COMMITMENT • CORPORATE SOCIAL RESPONSIBILITY.}

\section{Resumen}

Al considerar lasimplicaciones sociales de sus actividades, las empresas encuentran desafíos como el del comprometimiento de los stakeholders. El artículo examina esa reflexión en el ámbito del público interno de las organizaciones, debido a que su participación en proyectos corporativos puede estar condicionada a su comprometimiento con la organización. El objetivo fue estudiar la información y la comunicación y su relación con el comprometimiento. Los datos fueron recolectados mediante escalas de medidas y analizados por medio de técnicas estadísticas multivariadas. Se verificó que los empleados satisfechos con la información de los directivos, que tienen acceso a la comunicación vertical y la información estratégica son los más comprometidos. 


\section{ANO 10 • NÚMERO $19 \cdot 2$ 2oㅡ 2013 • ORGANICOM \\ INFORMAÇÃO, COMUNICAÇÃO E COMPROMETIMENTO:

crescente interesse em responsabilidade social empresarial (RSE) nos últimos anos vem acompanhando o advento da globalização e do comércio internacional, que também tem se refletido na maior complexidade dos negócios e em novas demandas por mais transparência e cidadania corporativa. Enquanto os governos têm tradicionalmente assumido a responsabilidade pela melhoria das condições de vida da população, as necessidades da sociedade têm excedido a sua capacidade para atendê-las (Jamali; Mirshak, 2007). Nesse contexto, o foco tem se voltado para o papel das empresas na sociedade, as quais, com uma gestão mais alinhada com a visão atual de negócios e mercado, estão buscando se diferenciar por meio do engajamento nas práticas de RSE.

O alcance dos temas envolvidos nas questões da RSE é mundial, o que fomenta uma significativa diversidade de conceitos, que enfatizam diferentes áreas. Assim, para alguns autores (Cavett-Goodwin, 2007), a definição do Banco Mundial parece ser a mais contemporânea e aplicável na maioria dos casos: a responsabilidade social corporativa é o comprometimento das empresas em contribuir para o desenvolvimento econômico sustentável, trabalhando com os empregados, com as suas famílias, com a comunidade local e com a sociedade em geral para melhorar as suas vidas de forma que seja bom para os negócios e para o desenvolvimento (WBCSD, 2001).

\section{RESPONSABILIDADE SOCIAL E DESENVOLVIMENTO SUSTENTÁVEL}

\section{Implicações organizacionais}

A aproximação dos conceitos de RSE e desenvolvimento sustentável é identificada nos anos 1960, quando pesquisadores buscavam compreender melhor a relação entre organizações e o desenvolvimento sustentável da sociedade (Carrol, 1991). Ainda que o significado da atuação socialmente responsável ainda não esteja completamente circunscrito em termos de pesquisa, existe um crescimento mundial importante de iniciativas e conceitos de RSE (Carrol, 1991; Kakabadse e Rozuel, 2005; Arruda e Pereira, 2009)!. A dimensão ética é apresentada por alguns autores, como Francisco Melo Neto e César Froes (2001) como sendo a principal dimensão da RSE. Ou seja, a ética pode ser considerada um pressuposto da empresa socialmente responsável, uma vez que o exercício da RSE está vinculado ao comportamento ético da organização. Nesse contexto, os trabalhadores têm um papel fundamental, pois não se trata de um engajamento restrito aos gestores da empresa, mas diz respeito a todos os funcionários, em todos os níveis. 0 comprometimento do funcionário com o comportamento socialmente responsável da organização também é um fator de legitimação da empresa socialmente responsável e pode definir o sucesso ou o fracasso de suas iniciativas. Por isso, o engajamento das partes interessadas (stakeholders), e entre elas os trabalhadores, na atuação responsável das empresas, é um tema que tem ganhado força em nível mundial.

Na Conferência Ethos Internacional 2012, foi lançada a iniciativa global "As empresas e suas relações com stakeholders. Engajamento:uma estratégia de inovação". Trata-se de um debate global cuja plataforma-www.criticalfriendsinternacional. com - organiza informações e recursos sobre o engajamento de partes interessadas.

Há um consenso de que uma abordagem inclusiva das partes interessadas é crítica, não apenas para dar credibilidade e responder às demandas dessas partes em serem ouvidas, mas também para impulsionar o conhecimento, a inovação e o desempenho no âmbito do negócio. (...) As abordagens de informação e comunicação com as partes interessadas estão evoluindo lentamente para o engajamento com as partes interessadas, indo em direção à cooperação entre empresa e partes interessadas e, em alguns

1 No Brasil, destaca-se a atuação do Instituto Ethos, cujo objetivo é "disseminar a prática da responsabilidade social empresarial, ajudando as empresas a compreender e incorporar critérios de responsabilidade social de forma progressiva e a implementar políticas e práticas com critérios éticos". (Disponível em www.ethos.org.br; acesso em 15 ago. 2012). 
casos, para o envolvimento das partes interessadas em projetos de inovação ou na governança corporativa da empresa. Nos próximos anos e décadas, esse novo paradigma de um trabalho aberto e colaborativo no âmbito da sustentabilidade será, sem dúvida, a chave para construir uma resiliência corporativa - uma abordagem mais saudável à adaptação econômica do que a sobrevivência dos mais fortes (Critical Friends, 2012).

A informação e a comunicação, grifadas na citação acima, estão na base das questões relativas ao engajamento e cristalizadas nas normas internacionais ${ }^{2}$ que tratam da significância, qualidade e gestão da informação para o engajamento das partes interessadas. Ou seja, a relação entre informação-comunicação e o engajamento para a RSE parece estar bem consolidada, uma vez que a normatização internacional representa a evolução tanto das práticas como das pesquisas na área. Além de cristalizar os conceitos e representar formalmente um estágio avançado de gestão da RSE, a normatização tem um papel importante também para as empresas que se encontram em fases iniciais ou apenas intencionais em termos de gestão socialmente responsável. Para essas empresas, o conteúdo das normas e os princípios que as fundamentam podem servir como parâmetro de orientação para ações futuras.

Por outro lado, ao considerar as implicações sociais de suas atividades, as organizações se defrontam com desafios que vão além da regulamentação existente. As questões relativas às partes interessadas e, no caso do presente estudo, os funcionários, são complexas e necessitam ser analisadas sob diferentes dimensões. 0 engajamento dos funcionários em projetos e ações corporativas passa por alguns fatores que condicionam a sua participação, como é o caso do comprometimento com a organização. Um funcionário que não está comprometido com a empresa dificilmente irá se engajar em seus projetos. 0 comprometimento, por sua vez, é considerado pela literatura acadêmica como um elemento complexo da vida organizacional e que sofre influência de diversos fatores. Neste artigo, o foco se situa na questão da informação e da comunicação e sua relação com o comprometimento dos funcionários. Mais especificamente, por meio de análises estatísticas, buscamos verificar se efetivamente a informação/comunicação interfere nos níveis de comprometimento, 0 que seria a base para a busca do engajamento dos funcionários na atuação socialmente responsável das empresas.

\section{Comprometimento}

0 comprometimento está se tornando um tema de discussão cada vez mais presente nas organizações, pois associa-se à busca de diferenciais competitivos (Dessler, 1997). Em especial, alguns estudos indicam que o comprometimento está fortemente relacionado ao absenteísmo, à assiduidade, à rotatividade, à pontualidade, aos comportamentos da cidadania, à aceitação das mudanças, ao desempenho dos membros organizacionais, à intenção de buscar outro emprego e ao abandono de emprego (Moscon, 2009; Allen e Meyer, 1996; Postmes et al., 2001). Segundo Vera L. Cançado, Patrícia Genelhu e Lúcio Flávio Renault de Moraes (2007, apud Moscon, 2009), as pesquisas sobre comprometimento no âmbito organizacional começam a aparecer na segunda metade do século XX. Todavia, conforme Moscon (2009), o conceito de comprometimento vem sendo trabalhado de forma mais frequente desde os anos 1980, com o estudo "The measurement of organizational commitment", de Richard Mowday, Richard Steers e Lyman Porter (1979), considerado um marco para a área. Na perspectiva de Antonio V. Bastos (1994, p. 78), a pesquisa pelo entendimento do que significa, de como interfere na organização e de que maneira se conquista o comprometimento organizacional "insere-se na longa tradição dos estudos que buscam identificar e compreender fatores pessoais que determinam o comportamento humano no trabalho". Ainda segundo Bastos (1994, p. 78), "o comprometimento passou a significar um estado do indivíduo; um estado de lealdade a algo relativamente duradouro e que pode ser analisado através de sentenças que descrevem intenções, sentimentos, desejos".

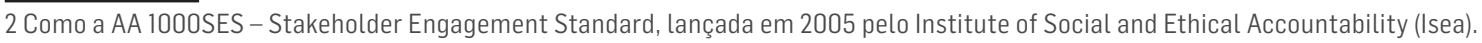


Na literatura é possível identificar uma convergência de definições relativas ao comprometimento, principalmente nos aspectos que dizem respeito à identificação de objetivos, metas e valores organizacionais; à disponibilidade, ao engajamento eà disposição para exercer esforços a favor da empresa; e, finalmente, ao desejo de permanecer como membro da organização (Bastos, 1994; Lisboa Filho e Godoy, 2006; Mowday, Steers e Porter 1979; Oliveira e Vieira, 1999).

A convergência dessas definições se situa nos aspectos que dizem respeito desde a relação emocional entre 0 indivíduo e a organização até os aspectos normativos e sociológicos dessa relação. Assim, o viés afetivo é assumido por diversos autores como sendo um vínculo emocional do indivíduo para com a organização na qual trabalha e com a qual se identifica. Este indivíduo acredita nos objetivos e valores da organização, assumindo-os como sendo seus. Além disso, possui o desejo de permanecer na organização por um longo período para o alcance desses objetivos e, por isso, se esforça em prol da organização. Outro viés importante nos estudos sobre o comprometimento é o instrumental calculativo, segundo o qual o comprometimento é visto como uma relação em que a recompensa é fundamental. 0 comprometimento instrumental se caracteriza pela relação de troca entre o indivíduo e organização. 0 colaborador exerce a sua função esperando obter retorno por parte da empresa. Já quando se trata de comprometimento normativo, o sistema cultural da organização pode definir os níveis de comprometimento (Lisboa Filho, Godoy, 2006). Sobre a abordagem comportamental, Lisboa Filho e Godoy (2006, p. 5) afirmam que: "as pessoas tornar-se-ão comprometidas a partir de suas próprias ações, que, por sua vez, refletem-se em comportamentos futuros, ocasionando a criação de um lento, porém resistente vínculo com a organização". Os vínculos da subordinação são tratados pela abordagem sociológica segundo a qual as relações de autoridade "governam o controle do empregador e a subordinação do empregado" (Bastos, 1996, p. 97).

De acordo com John Meyer e Natalie Allen (1991), mesmo que estabelecendo vínculos de diferentes naturezas, um indivíduo pode desenvolver diferentes tipos de comprometimento que podem ocorrer conjuntamente. Algumas variáveis podem influenciar o desenvolvimento desses vínculos, dentre elas a comunicação. Desde os anos 1970, alguns estudos organizacionais observam que a comunicação tem criado condições para um melhor exercício do comprometimento organizacional (Katz e Kahn, 1972; Foy, 1994; Meyer e Allen, 1997). As constantes transformações no ambiente de negócios demandam que haja uma conexão direta entre a organização e o trabalhador, fazendo com que o processo de comunicação ${ }^{3}$ se apresente como agente catalisador de informações que estimule a identificação do indivíduo com os objetivos da organização e favoreça o comprometimento (Brum, 2000).

0 ambiente social e econômico sofre mudanças e, atualmente, o processo de informação e comunicação interna desenvolvido por muitas empresas representa uma via na operacionalização de um novo paradigma, centrado na ética, na responsabilidade social, na cidadania corporativa e no desenvolvimento sustentável. Acrescenta-se que essa relação entre comunicação interna e responsabilidade social é necessária para romper com um modelo empresarial e econômico apenas focalizado nos resultados financeiros para a tomada de decisão.

\section{Comunicação, informação e comprometimento}

Com a evolução dos processos comunicativos organizacionais, diversos meios de comunicação podem contribuir para facilitar, ou não, os relacionamentos e trocas de informações entre indivíduos no âmbito das empresas. Esses meios apresentam enormes vantagens à medida que transpõem barreiras entre colaboradores de diferentes níveis hierárquicos, além de fazer com que as informações sejam repassadas rapidamente entre setores de forma econômica e menos propensa a distorções (Lima, 2003).

3 Para Tavares (2005, p. 49), "a comunicação é uma das variáveis que precedem o comprometimento dos funcionários. Ela é essencial para o bom funcionamento de qualquer tipo de instituição, pois é por meio dela que uma organização se relaciona com o meio ambiente e suas partes". 
De acordo com Alex Mucchielli (1995), o processo de transmissão da informação nasce do encontro efetivo de uma informação com um indivíduo. Esse encontro depende, sobretudo, do interesse e do projeto pessoal do indivíduo. Nessa perspectiva, o autor evidencia que uma informação não está inscrita num espaço em branco, mas sim num espaço constituído de representações que podem ser reorganizadas. Por outro lado, comunicar é transmitir uma mensagem, uma informação capaz de modificar as representações do outro, agir sobre o outro e ainda fazer prova de uma influência sobre o outro. Nesse sentido, 0 ato de comunicar produz efeitos nos níveis cognitivos e relacionais do indivíduo.

ParaDominique Wolton(1999), a informação tem por objetivo colocar o mundo em "forma", ou seja, reportar os acontecimentos e fatos, além de contribuir para o funcionamento das sociedades complexas. Ela é inseparável da comunicação, que, além do ideal normativo de troca e interação, constitui-se enquanto meio difusor de informações e construtor de representações.

Já os atuais modelos de comunicação organizacional evidenciam as diferentes formas de como a informação é transmitida no seio de uma organização (Bouzon et al. 2006; Dollan et al., 2007). Nesse sentido, a comunicação organizacional se apresenta enquanto meio que possibilita ter acesso ao(s) outro(s), integrando as diferentes partes que formam a organização, coordenando suas atividades e cumprindo sua finalidade (Lima, 2003).

Um estudo realizado por Tom Postmes et al (2001) revela que há uma relação substancial entre comunicação e comprometimento organizacional. No entanto, essa relação varia fortemente em função do tipo de comunicação. Em sua pesquisa, Gary Dessler (1997) aponta que funcionários dão mais importância à existência de um fluxo de comunicação honesto do que a uma maior segurança no emprego. 0 autor evidencia ainda que grandes empresas apresentam alto nível de comprometimento e utilizam o fluxo de comunicação contínuo e recíproco para conquistar a confiança dos seus colaboradores.

As teorias organizacionais de Foy (1994) e Vicky Smith (1997) revelam que a comunicação horizontal (informal e socioemocional) é considera extremamente relevante no processo do comprometimento organizacional. Essa concepção relacional procura evidenciar a importância das relações humanas no contexto organizacional, reforçando que as relações informais são eixos essenciais nessa perspectiva.

Todavia, algumas pesquisas empíricas tendem a contrapor essa ideia. A pesquisa conduzida por Postmes et al (2001), por exemplo, enfatiza que a relação entre comunicação e comprometimento não é igualmente forte para todos os tipos de comunicação $0^{4}$. Essa pesquisa revela ainda que os funcionários são fortemente comprometidos quando obtêm informações adequadas para a execução de suas tarefas, sendo as informações apresentadas a eles a partir de canais formais e/ou burocráticos. 0 processo de comunicação com colegas próximos ou superiores imediatos, com conteúdo socioemocional, a partir de canais informais, revelou um menor nível de comprometimento dos funcionários. A pesquisa demonstrou, ainda, que a relação entre comunicação e comprometimento é mais forte em grandes organizações.

Outra pesquisa empírica, realizada por Marília Falcioni (2009), buscou verificar se existe relação entre comprometimento afetivo dos funcionários e a existência de uma comunicação interna percebida como eficaz. As análises indicaram que há uma associação entre cada cruzamento de variáveis da comunicação interna e do comprometimento. A pesquisa possibilitou

4 Os tipos e/ou fluxos de comunicação na pesquisa foram organizados da seguinte forma: comunicação para cima (ascendente), para baixo (descendente) ou horizontal (lateral). 
observar que todas essas variáveis se mostraram correlacionadas, no mínimo, moderadamente. Tanto a pesquisa de Postmes et al. (2001) quanto a de Falcioni (2009) foram realizadas em setores específicos, tendo a amostra sido composta por diversas empresas com diferentes estratégias de comunicação interna. A correlação entre comprometimento e comunicação/informação foi estabelecida. Ainda assim, tais trabalhos suscitam uma reflexão a respeito dos diferentes níveis de exposição dos entrevistados à informação, já que atuavam em empresas distintas. É nesse ponto que o presente artigo busca avançar, uma vez que a pesquisa foi realizada com trabalhadores que recebem informação organizada, sistematizada e com periodicidade controlada.

\section{METODOLOGIA}

Nossa pesquisa constitui-se em um estudo empírico, que se vale de métodos quantitativos para a análise das relações entre as variáveis estudadas. 0 instrumento utilizado para a coleta de dados é uma escala de Lickert, desenvolvida e validada por Postmes et al. (2001). A opção pelo método quantitativo para estudar a relação entre as variáveis, bem como a definição pelo uso de escalas, está associada à natureza dessas relações e ao campo de estudo, conforme descrito a seguir.

Diante das considerações apresentadas na revisão teórica do presente artigo, noções como comprometimento, comunicação e engajamento surgem como fenômenos emergentes que requerem um importante esforço de investigação, o qual contemple alternativas não tradicionais em termos de métodos de pesquisa.

Uma dessas alternativas é a utilização de escalas, com vistas a, dentre outros aspectos, tornar mais objetiva a coleta de dados. Essa objetivação ocorre por meio do relacionamento dos fenômenos estudados com dados quantificáveis, seguindo determinadas regras, utilizando-se escalas para medir/quantificar as variáveis.

Todavia, em determinadas situações de pesquisa, as variáveis não são simples de serem medidas, constituindo-se de conceitos ou construtos ${ }^{5}$ mais elaborados, que são fenômenos não-observáveis, similares a variáveis latentes, que necessitam de definição dos seus elementos para serem compreendidos. Nestes casos, quando há necessidade de medir a ocorrência de um construto envolvendo diversas dimensões, devem-se utilizar escalas múltiplas, também chamadas de escalas multi-itens.

É a partir dessa perspectiva que o uso de escalas é considerado como uma importante possibilidade para a pesquisa na área da comunicação, principalmente no que se refere a aspectos constituintes de fenômenos contemporâneos, como é o caso da gestão da comunicação, suas possibilidades metodológicas e sua relação com o comprometimento dos funcionários como base para a atuação socialmente responsável das organizações. Desse modo, uma vez que a escala seja validada, ela pode oferecer subsídios para intervenções mais adequadas à realidade das organizações.

Neste trabalho, o comprometimento é considerado como suporte para o engajamento dos funcionários das empresas em seus projetos de responsabilidade social. Além disso, considerando o conjunto de resultados obtidos em pesquisas anteriores (Postmes et al., 2001; Falcioni, 2009), o presente estudo se fundamenta nas relações já identificadas entre comunicação, informação e comprometimento, especificamente numa situação em que os funcionários estão expostos a intensas ações

5 De acordo com Edwards e Bagozzi (2000), um construto é um termo conceitual utilizado para descrever um fenômeno de interesse teórico. 
de comunicação. Ou seja, o que se busca verificar é se o comprometimento está associado às ações formais de comunicação da empresa, à comunicação com a liderança ou à comunicação entre as equipes. Assim, para a realização da pesquisa, 0 campo de estudo foi uma empresa que possui um setor de comunicação interna bem estruturado e com intensa produção de informação para os funcionários. A empresa analisada, aqui denominada ficticiamente como Alfa, é uma empresa globalizada ${ }^{6}$ que atua no setor metal-mecânico há mais de sessenta anos. Nas unidades de Caxias do Sul (RS), a Alfa possui em torno de 8,3 mil colaboradores, completando um quadro de 16 mil funcionários entre todas as unidades.

A comunicação com os funcionários da Alfa é por meio de veículos de comunicação que são de responsabilidade do setor de comunicação interna. Esse setor é formado por profissionais de relações públicas que têm a responsabilidade de manter atualizados os veículos internos de comunicação. Essa equipe se ocupa da gestão de meios como a intranet, quadros murais, tevê corporativa e revista interna mensal, todos com o objetivo de manter informada a equipe de funcionários. Tais informações possuem conteúdo corporativo, sendo disseminadas para todas as unidades do Brasil, o que gera uma intensa dinâmica de informação da empresa para seus funcionários.

0 instrumento utilizado para a coleta de dados foi a escala multi-itens desenvolvida por Postmes et al. (2001). Ela está estruturada em sete blocos de perguntas: (1) Dados pessoais; (2) Dados profissionais; (3) Quantidade de informações estratégicas; (4) A comunicação de cima para baixo; (5) Satisfação com o retorno das respostas dos gestores; (6) A comunicação entre departamentos; (7) Comprometimento com a organização.

O instrumento de coleta de dados foi enviado por correio eletrônico (e-mail) para os funcionários do setor administrativo da Alfa e por meio de cópia física para os funcionários do setor fabril nas duas unidades localizadas em Caxias do Sul. Foram distribuídos quatrocentos formulários de pesquisas. Destes, 250 foram formulários impressos e 150 por correio eletrônico (e-mail). 0 retorno foi de trezentos questionários, sendo 192 impressos e 108 recebidos via e-mail, dos quais cinco foram excluídos por não cumprirem as exigências de utilizar vários pontos da escala para resposta das questões, totalizando uma amostra de 295 questionários válidos.

Após validados, os dados foram digitados e analisados utilizando-se o software IBM SPSS, por meio do qual foram realizados procedimentos de validação do instrumento e análises descritivas e inferenciais, a seguir apresentadas.

\section{RESULTADOS}

Os respondentes eram principalmente do sexo masculino (73\%), com escolaridade de ensino fundamental (54\%) ou superior (32\%). Dos participantes, $77 \%$ tinham dez ou menos anos de empresa e trabalhavam nas áreas administrativa ou de produção. Essas proporções são similares às observadas no conjunto dos funcionários, indicando a representatividade da amostra.

A escala estruturada a partir dos aspectos relativos à quantidade de informações estratégicas, comunicação de cima para baixo, satisfação com o retorno das respostas dos gestores, comunicação entre departamentos e comprometimento com a organização foi submetida a análises de validade e confiabilidade, por meio da análise fatorial exploratória, avaliação da consistência interna e correlações. A Tabela 1 apresenta os resultados obtidos com estas análises.

6 Situada na cidade de Caxias do Sul, no Rio Grande do Sul, a empresa conta com uma unidade fabril no Rio de Janeiro e outras no exterior, em países como África do Sul, Argentina, Colômbia, Egito, Índia e México. 
ANO 10 • NÚMERO $19 \cdot 2^{2}$ sem 2013 • ORGANICOM

INFORMAÇÃO, COMUNICAÇÃO E COMPROMETIMENTO:

Tabela 1 - Análises de validade e confiabilidade da escala.

\begin{tabular}{|c|c|c|c|c|}
\hline BLOCOS & QUANTIDADE & ANÁLISE FATORIAL & KMO & ALFA DE CRONBACH \\
\hline Quantidade de informações estratégicas & 5 & Unidimensional & 0,716 & 0,735 \\
\hline Comunicação de cima para baixo & 4 & Unidimensional & 0,672 & 0,611 \\
\hline Satisfação com o retorno das respostas dos gestores & 3 & Unidimensional & 0,620 & 0,707 \\
\hline Comunicação entre departamentos: & 3 & Unidimensional & 0,530 & 0,459 \\
\hline Comprometimento com a organização & 5 & Unidimensional & 0,814 & 0,930 \\
\hline
\end{tabular}

Os valores da medida de adequação da amostra de Kaiser-Mayer-Olkin (KMO) estão dentro da faixa de aceitação, que, conforme sugerem Hair et al. (2005), devem ser superiores a 0,5. Quanto à análise fatorial , todos os fatores se mostraram unidimensionais pelocritério do autovalor maior que1,0, indicando que cada fator realmenteera percebido pelos respondentes como sendo resultado de uma única dimensão. A consistência interna, medida pelo coeficiente alfa de Cronbach, indica 0 grau em que as respostas são consistentes entre os itens de uma mesma medida (Kline, 2005), ou, dito de outra forma, que há coerência nas respostas dadas pelos respondentes. São aceitáveis valores acima de 0,6 (Hair Jr. et al., 2005; Malhotra, 2006; Nunnaly, 1978). Observa-se que somente o aspecto da comunicação entre departamentos apresentou valor baixo, 0 que pode ser consequência do porte da organização e da diferença entre os setores dos participantes.

Uma vez validada a amostra, passou-se à análise das correlações entre os blocos do instrumento, conforme pode ser verificado na Tabela 2. Todas as correlações foram significativas ao nível de significância 0,001.

Tabela 2 - Correlação entre os blocos.

\begin{tabular}{|c|c|c|c|c|}
\hline BLOCOS & $\begin{array}{c}\text { COMUNICACÃO DE } \\
\text { CIMA PRABAIXO }\end{array}$ & $\begin{array}{c}\text { SATISFACÃO COM O } \\
\text { RETRNO DASRESPOSTAS } \\
\text { DOS GESTORES }\end{array}$ & $\begin{array}{c}\text { COMUNICAC̃OENTRE } \\
\text { DEPARTAMENTOS }\end{array}$ & $\begin{array}{c}\text { COMPROMETIMENTO } \\
\text { ORGANIZACIONAL }\end{array}$ \\
\hline Quantidade de informações estratégicas & 0,323 & 0,487 & 0,381 \\
\hline Comunicação de cima para baixo & & 0,334 & 0,342 \\
\hline Satisfação com o retorno das respostas dos gestores & & 0,361 & 0,448 \\
\hline Comunicação entre departamentos & & & 0,369 \\
\hline
\end{tabular}

Analisando-se as correlações, verifica-se que o "comprometimento organizacional" é mais associado com a "satisfação dos funcionários com as respostas dos gestores" e com a "quantidade de informações estratégicas recebidas", sugerindo que a comunicação vertical é mais importante para o comprometimento do que a comunicação horizontal (comunicação entre departamentos).

Na sequência, procedeu-se à análise de regressão múltipla , considerando o bloco "comprometimento com a organização" como sendo a variável dependente e as demais variáveis independentes ou preditoras. 0 modelo resultante é significativo e indica que, entre os componentes que explicam o comprometimento, aqueles testados no instrumento são responsáveis por 0,257 da variabilidade do "comprometimento com a organização". Dito de outra forma, o resultado da análise de regressão múltipla indica que $25,7 \%$ do comprometimento com a organização ocorre devido a fatores de comunicação/informação. 
A Tabela 3 apresenta os resultados obtidos na análise de regressão múltipla, tendo o comprometimento com a organização como variável dependente.

Tabela 3 - Análise de regressão múltipla.

\begin{tabular}{|c|c|c|c|c|c|}
\hline FATORES & B & ERRO PADRÃO & BETA & t & SIG. \\
\hline Constante & 0,179 & 0,326 & - & 0,550 & 0,583 \\
\hline Quantidade de informações estratégicas & 0,351 & 0,127 & 0,167 & 2,765 & 0,006 \\
\hline Comunicação de cima para baixo & 0,378 & 0,112 & 0,190 & 3,374 & 0,001 \\
\hline Satisfação com o retorno das respostas dos gestores & 0,237 & 0,073 & 0,203 & 3,249 & 0,001 \\
\hline Comunicação entre departamentos & 0,230 & 0,095 & 0,144 & 2,422 & 0,016 \\
\hline
\end{tabular}

Com base nos resultados, pode-se afirmar que todos os fatores foram significativos e devem ser considerados no modelo de regressão, ou seja, todos esses fatores contribuem no entendimento do que gera comprometimento organizacional.

A análise dos valores dos betas gerados no modelo de regressão indica que o aspecto referente à "satisfação com o retorno das respostas dos gestores" é o que mais influencia o comprometimento com a organização. Esse resultado significa que esse fator é o que tem maior poder de explicar a variabilidade do comprometimento organizacional. Disso, observa-se que, em ordem de importância, a "comunicação de cima para baixo" ocupa a segunda posição. Ou seja, o fator "comunicação de cima para baixo", mantidos os valores dos outros fatores constantes, é o que também tem papel importante na explicação do comprometimento organizacional. Seguindo essa linha, a "quantidade de informações estratégicas" aparece na terceira posição. Esses três fatores evidenciam a importância que os funcionários atribuem à comunicação vertical.

A "comunicação entre departamentos", que seria um indicador da comunicação horizontal, também é importante, porém foi o fator que apresentou menor poder de explicação da variabilidade do comprometimento organizacional.

\section{CONSIDERAÇÕES FINAIS}

Na atualidade, o nível de informação e conscientização da sociedade cresce exponencialmente, o que gera efeitos na gestão das organizações. Nesse sentido, elas são provocadas a assumirem novas responsabilidades, além das já definidas pela ordem econômica centrada no mercado, regida pela minimização de custos e maximização de lucros. Ou seja, cuidar do meio ambiente e das pessoas que estão no seu entorno é uma das funções das empresas. Com o passar dos anos, mais do que uma função, isso passou a ser uma necessidade das organizações, as quais são cada vez mais consideradas como corresponsáveis pelo desenvolvimento e bem-estar do ambiente onde escolheram se instalar e das pessoas com as quais se relacionam.

Isso implica a crescente relevância do tema RSE no contexto socioeconômico mundial, aumentando a demanda pela busca do entendimento dos fatores que constituem esse que é considerado um importante pilar da sustentabilidade das organizações. Nesse cenário, surge a necessidade de as organizações estarem comprometidas com o seu público interno, investindo no seu desenvolvimento pessoal e profissional, buscando proporcionar melhorias constantes no ambiente de trabalho. 


\section{ANO 10 • NÚMERO $19 \cdot 2^{2}$ sem 2013 • ORGANICOM \\ INFORMAÇÃO, COMUNICAÇÃO E COMPROMETIMENTO: UM DESAFIO PARA O ENGAJAMENTO DO PÚBLICO INTERNO}

A contraparte dessa atitude da gestão é que o comprometimento do público interno com as práticas socialmente responsáveis das organizações torna-se um fator decisivo para o alcance da legitimação ou não de suas ações e, consequentemente, do sucesso ou fracasso das mesmas. Ou seja, é também o engajamento do público interno que dará credibilidade aos projetos de responsabilidade social ou, do contrário, pode torná-los ações vazias que, ainda hoje, em muitos casos, servem apenas para ilustrar relatórios de balanço social.

Dito de outro modo, o engajamento dos funcionários em projetos e ações institucionais também é influenciado por fatores que condicionam a participação dos mesmos, sendo um dos mais importantes o comprometimento com a organização. De fato, um funcionário que não está comprometido com a empresa na qual trabal ha dificilmente irá engajar-se voluntariamente em seus projetos, sejam eles de responsabilidade social ou não.

Nesse contexto, também tem crescido o nível de consciência dos gestores quanto à importância da comunicação no desenvolvimento da cultura de responsabilidade social, partindo da estratégia de contínua aproximação dos e com os seus públicos. Isso significa que hoje a comunicação de excelência é indissociável do exercício da cidadania, da gestão da responsabilidade social, do respeito à diversidade e da valorização profissional e pessoal. 0 cultivo do diálogo, da transparência e da interação permanente com o meio ambiente (a comunidade, o mercado, a sociedade em geral) e com os funcionários passa a ser fundamentos da sustentabilidade.

No contexto do presente trabalho, cujo objetivo foi estudar a informação e a comunicação e sua relação com o comprometimento, os resultados da pesquisa revelam que a satisfação com a informação/comunicação pode influenciar o comprometimento organizacional. Ou seja, funcionários que declararam possuir maior nível de satisfação com o retorno das respostas dos gestores, que têm acesso a maiores níveis de comunicação vertical, que recebem maiores quantidades de informações estratégicas e para os quais a comunicação entre departamentos é mais forte tendem a ser aqueles mais comprometidos com a organização.

Outro aspecto evidenciado pelo modelo de regressão aplicado aos resultados indica que a comunicação vertical é a variável que melhor explica o comprometimento. Os funcionários percebem como a informação é gerida "oficialmente" na empresa. Isto significa que a importância com que a empresa trata a comunicação (vertical) é percebida pelos funcionários e dá mais retorno em termos de comprometimento do que aquela informação que é obtida junto a colegas, pela troca de informações entre os departamentos (horizontal). Isso mostra que é importante que as organizações valorizem e explorem os canais formais de comunicação vertical, pois são eles que facilitam que os funcionários estejam mais comprometidos e, provavelmente, mais engajados nos projetos de RSE das organizações onde atuam.

Assim sendo, verificou-se que, efetivamente, a informação e a comunicação interferem nos níveis de comprometimento, considerado a base para a conquista do engajamento dos funcionários na atuação socialmente responsável das organizações.

\section{REFEREANCIAS}

ALLEN, Natalie J.; MEYER, John P. Affective, continuance, and normative commitment to the organization: an examination of construct validity. Journal of Vocational Behavior, n. 49, p. 252-276, 1996.

ARRUDA, Giovana Silva de; PEREIRA, Breno. A. Diniz. Estado da arte dos estudos sobre responsabilidade social empresarial (RSE) no Brasil. In: ENCONTRO DE ESTUDOS EM ESTRATÉGIA, IV, Recife, 2009. Anais eletrônicos. Rio de Janeiro: Anpad, 2009. Disponível em: <http://www.anpad.org.br/login.php?cod_edicao_subseca0=467\&cod_evento_edicao=43\&cod_ edicao_trabalho=10226>. Acesso em: 07 jul. 2011. 
BASTOS, Antônio V. Bittencourt. O conceito de comprometimento: sua natureza e papel nas explicações do papel humano no trabalho. Organização e Sociedade, Salvador, v. 1, n. 2, p. 77-106, 1994.

Comprometimento no trabalho: os caminhos da pesquisa e os seus desafios teórico-metodológicos. In: TAMAYO, Alvaro; BORGES-ANDRADE, Jairo Eduardo; CODO, Wanderley (Org.). Trabalho, organização e cultura. Coletâneas da Associação Nacional de Pesquisa e Pós-Graduação em Psicologia. São Paulo: Cooperativa de Autores Associados, 1996. p. 94-109.

BOUZON, Arlette et al. La communication organisationnelle en débat: champs, concepts, perspectives. Paris: L'Harmattan, 2006.

BRUM, Analisa de Medeiros. Um olhar sobre o marketing interno. Porto Alegre: L\&PM, 2000.

CARROLL, A. The pyramid of corporate social responsibility: toward the moral management of organizational stakeholders. Business Horizons, [s.l.], v. 34, n. 4, p. 39-48, 1991.

CAVETT-GOODWIN, David. Making the case for corporate social responsibility. 2007. Disponível em: <http://culturalshifts. com/archives/181>. Acesso: 28 ago. 2012.

CRITICAL FRIENDS. 0 que é engajamento de partes interessadas? 2012. Critical Friends. Disponível em: <http://www. criticalfriendsinternational.com/index.php/pt/background-pt/o-que-e-engajamento-de-partes-interessadas>. Acesso em: 15 ago. 2012).

DESSLER, Gary. Conquistando comprometimento: como construir e manter uma força de trabalho competitiva. São Paulo: Makron Books, 1997.

DOLAN, Simon L. et al. Psychologie du travail et comportement organisationnel. 3. ed. Montréal: Les Éditions de la Chenelière, 2007.

EDWARDS, Jeffrey R.; BAGOZZI, Richard P. On the nature and direction of relationships between constructs and measures. Psychological Methods, v. 5, n. 2, p. 155-174, 2000.

FALCIONI, Marília P. A influência da comunicação interna no comprometimento afetivo dos funcionários. Dissertação (Mestrado em Administração) - Centro de Estudos Sociais Aplicados da Universidade Estadual do Ceará. Fortaleza, 2009.

FOY, Nancy. Empowering people at work. Aldershot, UK: Gower, 1994.

HAIR JR., Joseph F. et al. Análise multivariada de dados. 5. ed. Porto Alegre: Bookman, 2005.

JAMALI, Dima; MIRSHAK, Ramez. Corporate social responsibility (CSR): theory and practice in a developing country context. Journal of Business Ethics, v. 72, n. 3, p. 243-262, 2007.

KAKABADSE, Nada K.; ROZUEL, Cécile. Corporate social responsibility and stakeholders approach: a conceptual review. International Journal of Business Governance and Ethics, v. 1, n. 4, p. 277- 302, 2005.

KATZ, Daniel; KAHN, Robert L. The social psychology of organizations. 2. ed. New York: Wiley, 1972.

KLINE, Rex B. Principles and practice of structural equation modeling. 2. ed. New York: Guilford Press, 2005.

LIMA, Súsi Barcelos e. A comunicação organizacional rompendo barreiras. Revista CCEI - Urcamp, v. 7, n. 11, p. 32-37, 2003. 
LISBOA FILHO, Flavi Ferreia; GODOY, Leoni Pentiado. A contribuição da comunicação organizacional na obtenção do comprometimento dos colaboradores. In: CONGRESSO BRASILEIRO DE CIÊNCIAS DA COMUNICAÇÃO, 2006, UnB. Disponível em: <http://www.intercom.org.br/papers/nacionais/2006/resumos/R1318-2.pdf>. Acesso em: 15 jan. 2011.

MALHOTRA, Naresh K. Pesquisa de marketing: uma orientação aplicada. 6. ed. Porto Alegre: Bookman, 2006.

MEYER, John W.; ALLEN, Natalie J. Commitment in the workplace: theory, research, and application. London: Sage, 1997.

MOSCON, Daniela Campos Bahia. Teorias implícitas de trabalhador comprometido e estratégias cotidianas de gestão: uma análise qualitativa. 2009. 136 f. Dissertação (Mestrado em Administração) - Núcleo de Pós-graduação em Administração, Universidade Federal da Bahia, Salvador, 2009. CD-ROM.

MOWDAY, Richard T.; STEERS, Richard M.; PORTER, Lyman W. The measurement of organizational commitment. Journal of Vocational Behavior, v. 14, n. 2, p. 224-247, 1979.

MUCCHIELLI, Alex. Les sciences de l'information et de la communication. Paris: Hachette. 1995.

MELLO NETO, Francisco de; FROES, César. Gestão da responsabilidade social corporativa: o caso brasileiro. Rio de Janeiro: Qualitymark, 2001.

NUNNALLY, Jum C. Psychometric theory. 2 ed. New York: McGraw-Hill, 1978.

OLIVEIRA, Lúcia Maria Barbosa de; VIEIRA, Marcelo Milano Falcão (Org). Administração contemporânea: perspectivas estratégicas. São Paulo: Atlas, 1999.

POSTMES, Tom et al. Communication and commitment in organizations: a social identity approach. Group Processes \& Intergroup Relations, London, v. 4. n. 3, p. 227-246, 2001.

SMITH, Viccky. New forms of work organization. Annual Review of Sociology, n. 23, p. 315-339, 1997.

TAVARES, Rosalina Semedo de Andrade. A importância da comunicação interna para o desenvolvimento do comprometimento organizacional: um estudo de caso em empresa brasileira. Dissertação (Mestrado em Administração) - FEA-USP, 2005.

WOLTON, Dominique. Culture: le refoulé de l'Europe. Revue Hermès, n. 23-24, 1999.

WBCSD. The business case for sustainable development: making a difference towards the Johannesburg Summit 2002 and beyond. 2001. Disponível em: <http://www.wbcsd.org>. Acesso em: 25 ago. 2012.

Artigo recebido em 30.08.2013 e aprovado em 20.09.2013. 